\title{
Al-Ashoosh: a third-millennium BC desert settlement in the United Arab Emirates
}

\author{
F. Contreras ${ }^{1, *}$, N. Carcacer $^{1}$, J. Thomas ${ }^{1}$, D. Koljic ${ }^{1}$, M. Murray ${ }^{1}$, \\ R.M. Bukhash ${ }^{2}$, S.O. Al Abbar ${ }^{2}$, M. Boraik ${ }^{2} \&$ H.M. Zein ${ }^{2}$
}

The archaeological site of Al-Ashoosh is a third-millennium BC settlement located in the Rub al-Khali Desert (or Empty Quarter), $70 \mathrm{~km}$ south of Dubai in the United Arab Emirates (UAE) (Figure 1). This site provides an excellent example of the type of occupation of the inland deserts of the Oman peninsula during the period following the Holocene Climatic Optimum. Between November 2015 and May 2016, the Dubai Municipality and the Sanisera Archaeology Institute conducted excavations at the site of Al-Ashoosh. This site was discovered during two seasons of survey in 2002-2003. This survey work, undertaken by the Dubai Municipality and the Department of Antiquities of Jordan, identified 33 archaeological sites ranging in date from prehistory to the late Islamic period. In 2006-2007, more-detailed archaeological investigations of the area of Al-Ashoosh were conducted, including survey, excavation and geological sampling (Casana et al. 2009; Herrmann 2012; Contreras \& Carcacer 2016).

Al-Ashoosh extends to at least $1.3 \mathrm{ha}$ and is located in a fenced area of low dunes that surround a large mound $1.5-2 \mathrm{~m}$ in height. The site is divided into two distinct parts, labelled areas A and B (Figure 2). The first of these (the main area) covers around $350 \mathrm{~m}^{2}$ and represents a single-phase rubbish midden located on a natural sand dune. It has yielded a large amount of material including faunal remains, lithics, charcoal and a small quantity of pottery. There is no evidence for structures of any type, and the stratigraphy appears to have built up rapidly. A C14 radiocarbon test made from a charcoal layer gave a date of 3699 31 BP (SUERC-67025: 2164-2016 BC at 95.4\%; date modelled in OxCal v.4.2, using IntCal13 calibration curve (Reimer et al. 2013)).

Located $50 \mathrm{~m}$ to the south-west, area B has revealed eight complete combustion structures of oval/circular shape, varying in diameter from $0.4-1.6 \mathrm{~m}$, and in height between 0.1 and $0.4 \mathrm{~m}$ (Figure 3). Each of these features is constructed of an irregular clay ring that defines the inner and outer walls of the structures; on some of them, it is possible to perceive fingerprints. The internal walls are also made of clay, sloping down to the flat bases of the structures that sit directly on the bedrock. These may have been a type of tannour oven

1 Antiquities Section, Sanisera Archaeology Institute, 68 Post Office Box, 07740 Mercadal (Menorca), Illes Balears, Spain (Email: sanisera@arrakis.es)

2 Dubai Municipality-Architectural Heritage and Antiquities Department, Al-Shindagha, Restoration House, Dubai,UAE (Email:mbkarim@dm.gov.ae)

* Author for correspondence (Email: sanisera@arrakis.es)

(C) Antiquity Publications Ltd, 2016 ANTIQUITY 90 354, e3 (2016): 1-6 


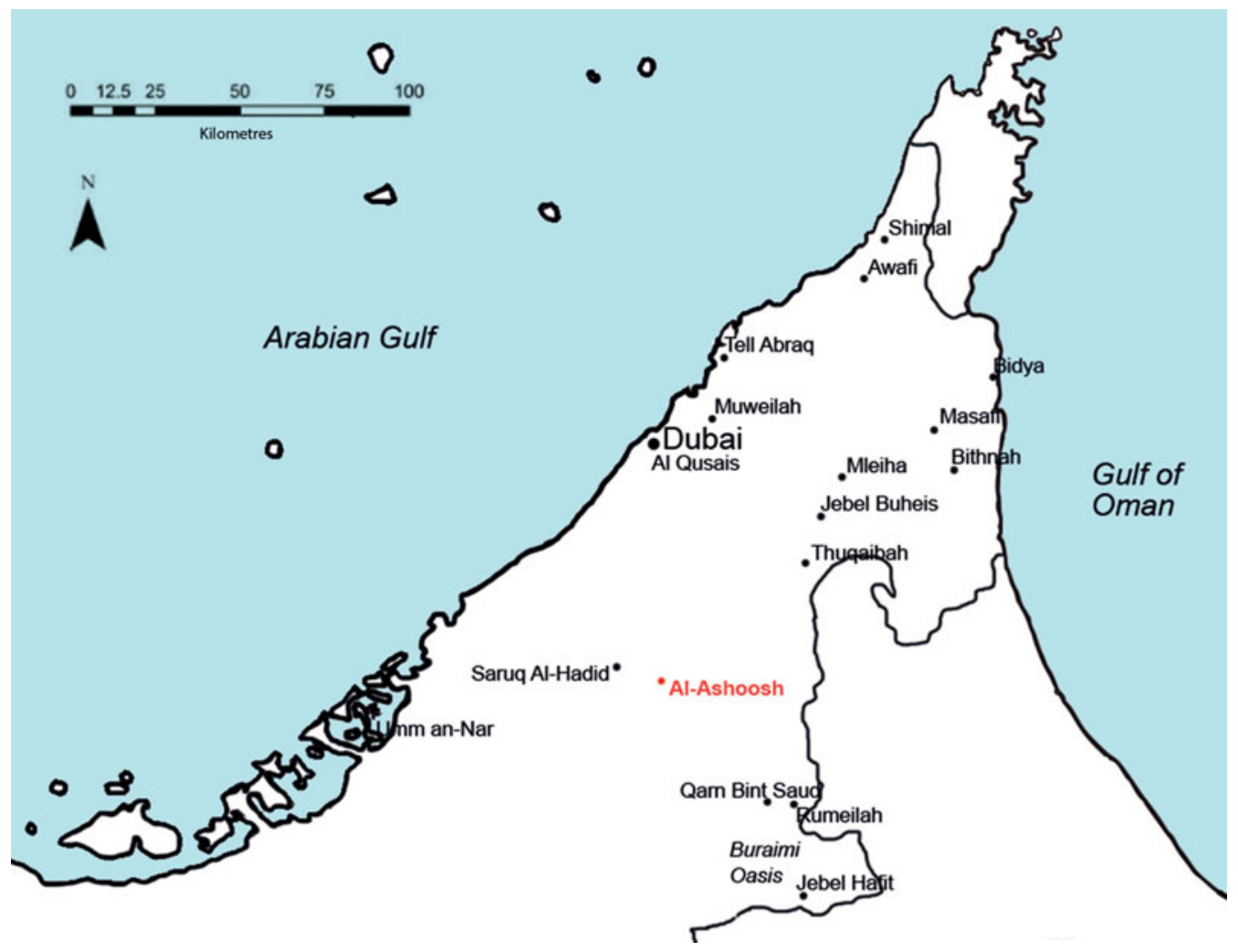

Figure 1. Map of the Emirate of Dubai, UAE, with archaeological sites.

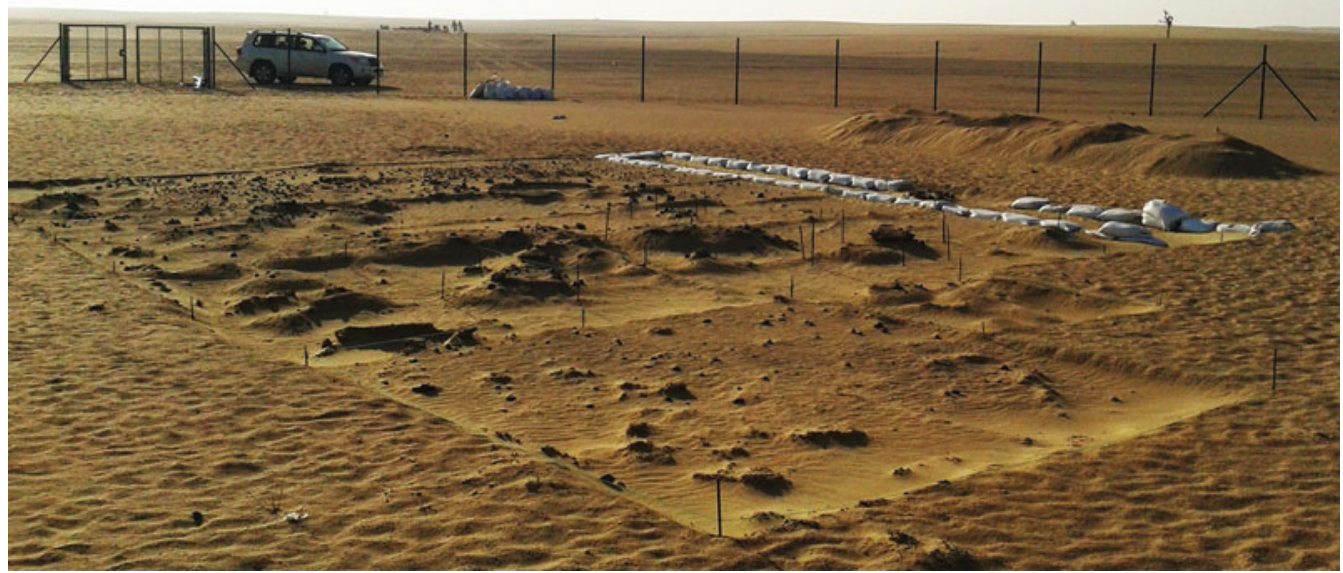

Figure 2. North-facing view of Al-Ashoosh, area B, UAE.

(C) Antiquity Publications Ltd, 2016 




Figure 3. Structure 1 (area B) at Al-Ashoosh.

or tandoor, a typical cylindrical oven used for cooking in Western, Southern and Central Asia. A C13/C12 radiocarbon test (Beta Analytic Radiocarbon Dating Laboratory: Beta-438477) from one of the charcoal deposits of these structures gave a date of 3900土30BP (Beta-438477: 24702290 BC at 95.4\%; date modelled in OxCal v.4.2, using IntCal13 calibration curve (Reimer et al. 2013)).

The different functions of areas $A$ and $B$ are reflected in the material culture recovered from each. Area A yielded large numbers of rocks and worked stone, and almost $300 \mathrm{~kg}$ of faunal remains. A remarkable find from this area is a steatite Gulf Type (or proto-Dilmun) seal with a scene of 'two drinking men' on the obverse (Figure 4). This image, derived from Babylonia, appeared c. $3000 \mathrm{BC}$, and then spread into the glyptic art of Dilmun. Circular stamp seals were in use from c. 2100-1650 BC, although this particular seal can be dated to c. 2050-2000 BC. The only other archaeological site from the UAE where a seal of the type similar to those from the Arabian Gulf has been found is Tell Abraq, yet there the seal did not depict this specific scene. Excavation of area B produced almost no faunal remains and fewer stones, but there was a higher number of pottery sherds and clay fragments, and concentrations of charcoal or production waste surrounding the eight combustion structures (Figure 5).

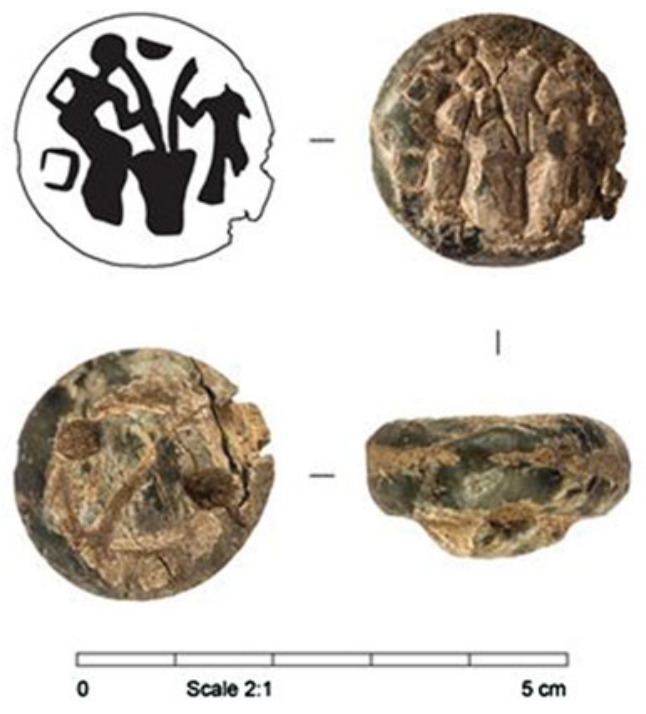

Figure 4. Seal found at Al-Ashoosh (drawing: Margot Murray; photography: Nico Becker).
A preliminary study of 134 stone tools from areas $A$ and $B$ shows that cores and piercers represent 47 per cent of the total, but bladelets, endscrapers and blades are also represented (Figure 6); a Fasad point was recovered, dating to 7000-5000 BC. Amongst the pottery, approximately 90 diagnostic sherds were identified, with similarities to Hili 8 (Al-Ain, UAE) and to Bahrain, particularly the black-on-red vessels of Umm an-Nar type 1, most of them of third-millennium BC date. Soft stone fragments from the Umm anNar period (2300-2000 BC) were also recovered from both areas.

Analysis of faunal material, through species identification, can contribute to knowledge of past climate, although our initial results neither support nor refute the hypothesis that the Rub' al Khali

(C) Antiquity Publications Ltd, 2016 


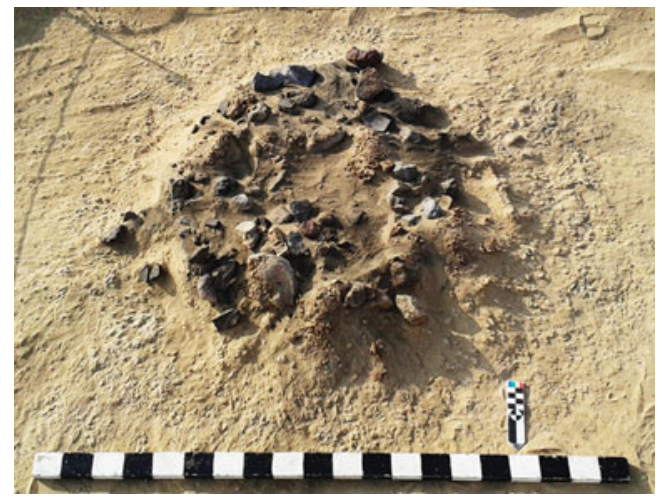

Figure 5. Charcoal concentration 2 (area B) at Al-Ashoosh. experienced a moist period during the third millennium $\mathrm{BC}$, as all of the species identified are suited to arid or semi-arid environments (Magee 2014: 197). The evidence for diet and economy is clearer. Identified species include camel, oryx, sheep/goat, gazelle and other medium to medium-large-sized animals, along with a medium-sized bird species and a canid (e.g. dog, jackal, fox). Figure 7 illustrates a minimum number of individuals for each taxon. Spiral fractures, cut marks and burning indicate that these animals were
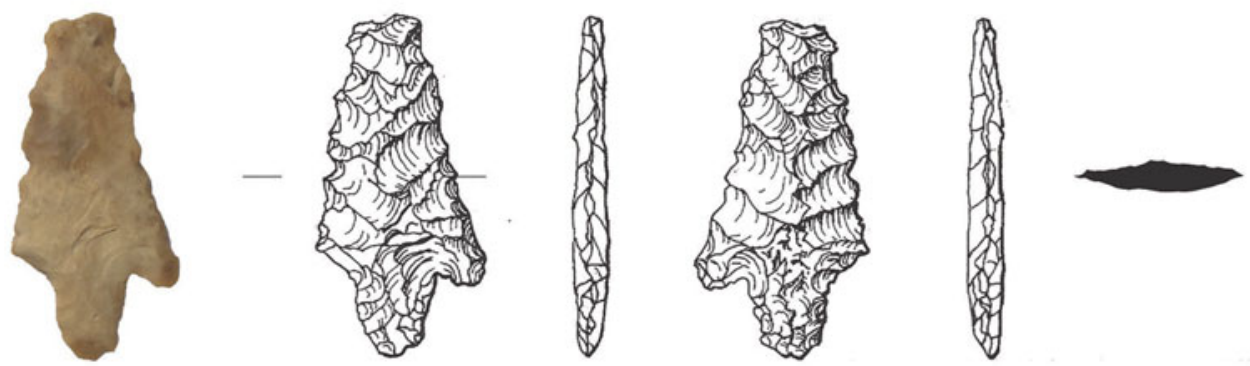

$\mathrm{B} / \mathrm{CC} 2 / 103 / 1$
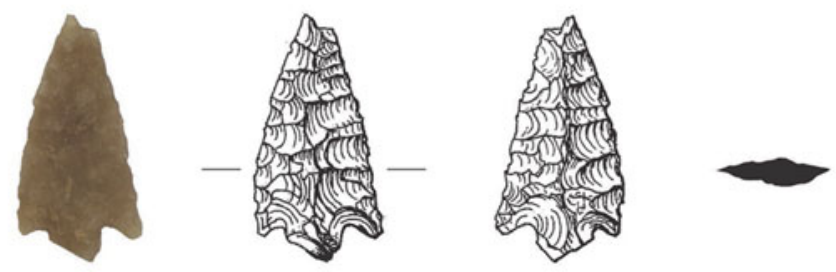

$\mathrm{A} / \mathrm{G} 2 / 127 / 1$

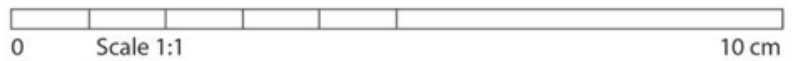

Figure 6. Stone arrowheads at Al-Ashoosh (drawing and photography: Margot Murray).

(C) Antiquity Publications Ltd, 2016 


\section{Identified Taxa}

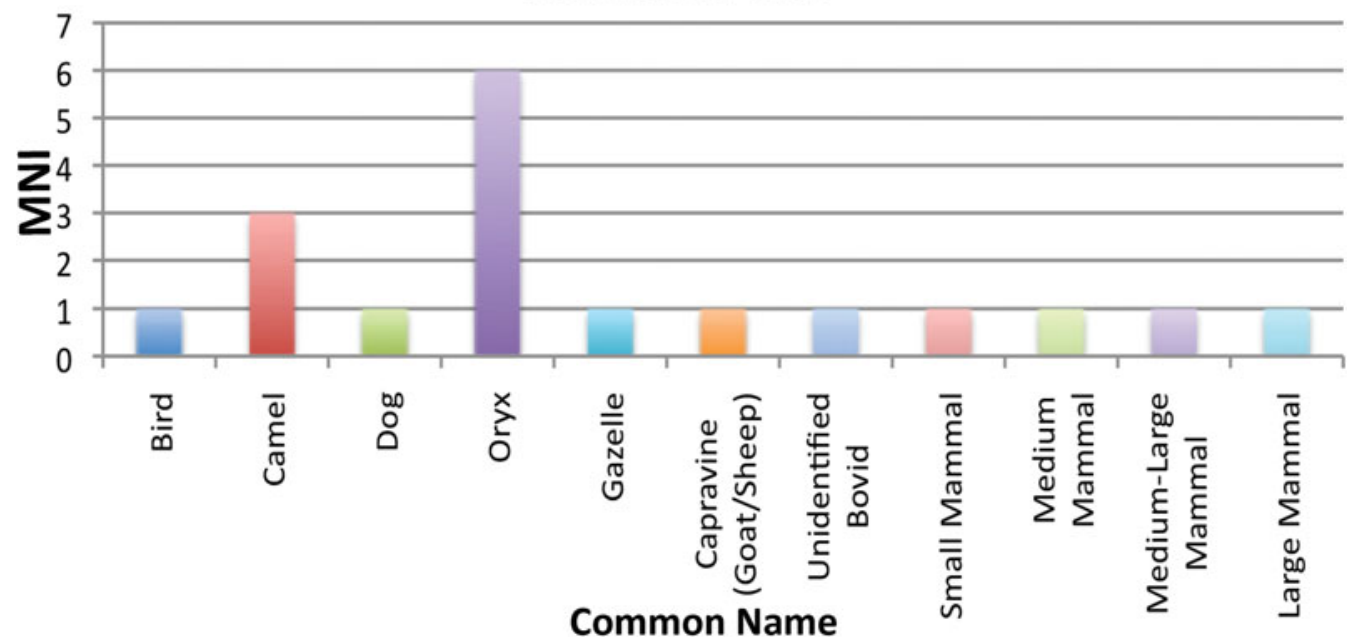

Figure 7. Taxa identified. Graph is based on minimum number of individuals (MNI).

butchered and cooked with the meat on the bone, potentially in the combustion featuresor tannour ovens — discussed above. Discarded food bones were used for fuel. The bird and canid remains show no signs of modification.

Of the taxa identified, the only known domesticated species in the region during the third millennium BC are cattle and sheep/goat. There are, however, no clear signs in terms of sex ratios, ages and pathologies that these species at Al-Ashoosh were domesticated, yet one bovid (cattle, sheep/goat) specimen has pathologies that would severely inhibit its survival in the wild (Figure 8). Although extremely tentative, this is the strongest indicator of nomadic pastoralism so far identified in the faunal material from Al-Ashoosh. The remains of cattle,

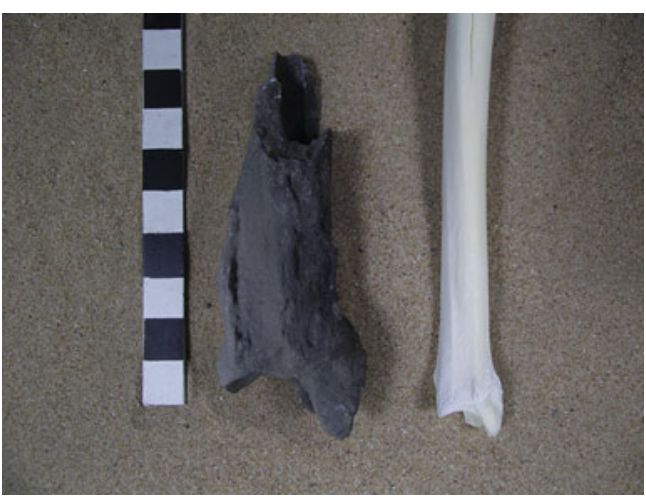

Figure 8. A pathological distal bovid tibia (left) shows evidence for burning. A modern, wild gazelle tibia (right) with no pathologies has been used for comparison. goats and sheep represent only four per cent of the total assemblage; this may suggest that if these animals were domesticated, their primary use would be for labour, wool, milk and, only when the animal became less productive, for meat.

The evidence of the camel bones suggests that wild animals were hunted for food during the third millennium BC. Only one young camel, aged less than ten months, has been identified to date; most of the animals were older juveniles, three to four years of age, and were therefore particularly attractive to hunters. This is also the age when the animals would be highly valuable to a herding community, as they are both (C) Antiquity Publications Ltd, 2016 
strong and sexually mature, potentially able to carry heavy loads or to produce milk and offspring. No pathologies or stress indicators associated with domestication have been observed.

Twenty years ago, Magee (1996: 211) challenged archaeologists to determine how and why prehistoric humans used the interior desert regions of the Arabian Peninsula. Inland deserts play a pivotal role in our understanding of settlement patterns, land use and environmental reconstruction during the Late Bronze Age (Herrmann 2012: 98). The preliminary results from the 2015-2016 fieldwork at Al-Ashoosh-a rare example of occupation in the Rub' al Khali during the Umm an-Nar period-provide insight into the habitat, diet and economy of the third millennium BC. Al-Ashoosh seems to have been a seasonal settlement occupied by a hunter/pastoral community, probably occupying structures of perishable materials, during the second half of the third millennium BC (2500-2000 BC). Al-Ashoosh was a place used for production, mainly of stone tools, as well as the dumping of high concentrations of faunal remains, pottery sherds, soft stone fragments and stone tools.

Al-Ashoosh provides an important example of a poorly known type of inland desert occupation in the Oman peninsula following the Holocene Climatic Optimum period, and greatly contributes to our understanding of the history of the UAE during the third millennium BC.

\section{References}

Casana, J., J.T. Herrmann \& S. Qandil. 2009. Settlement history in the eastern Rub al-Khali: preliminary report of the Dubai Desert Survey (2006-2007). Arabian Archaeology and Epigraphy 20: 30-45. http:

//dx.doi.org/10.1111/j.1600-0471.2008.00306.x

Contreras, F. \& N. Carcacer. 2016. Brief report of the archaeological excavations at Al-Ashoosh. Report prepared for Dubai Municipality, Dubai.

Herrmann, J.T. 2012. Prehistoric human ecodynamics in the Rub al-Khali Desert: results of remote sensing and excavations in Dubai, United Arab Emirates. Unpublished $\mathrm{PhD}$ dissertation, University of Arkansas. http: //dx.doi.org/10.1111/j.1600-0471.1996.tb00101.x

Magee, P. 1996. Excavations at Muweilah. Preliminary report on the first two seasons. Arabian Archaeology and Epigraphy 7: 195-213.

- 2014. The archaeology of prehistoric Arabia: adaptation and social formation from the Neolithic to the Iron Age. New York: Cambridge University Press.

Reimer, P.J., E. Bard, A. Bayliss, J.W. Beck, P.G. Blackwell, C. Bronk Ramsey, C.E. Buck, H. Cheng, R.L. Edwards, M. Friedrich, P.M. Grootes, T.P. Guilderson, H. Haflidason, I. Hajdas, C. Hatté, T.J. Heaton, D.L. Hoffmann, A.G. Hogg, K.A. Hughen, K.F. Kaiser, B. Kromer, S.W. Manning, M. Niu, R.W. Reimer, D.A. Richards, E.M. Scott, J.R. Southon, R.A. Staff, C.S.M. Turney \& J. VAN DER PLICHT. 2013. IntCal13 and Marine13 radiocarbon age calibration curves $0-50,000$ years cal BP. Radiocarbon 55: 1869-87. http://dx.doi.org/10.2458/azu_js_rc.55.16947 